\title{
AVALIAÇÃO DO ESTADO NUTRICIONAL DE AGROECOSSISTEMAS DE CAFÉ ORGÂNICO NO ESTADO DE MINAS GERAIS ${ }^{1}$
}

\author{
VANESSA CRISTINA DE ALMEIDA THEODORO ${ }^{2}$ \\ JANICE GUEDES DE CARVALHO ${ }^{3}$ \\ JOÃO BATISTA CORRÊA ${ }^{4}$ \\ RUBENS JOSÉ GUIMARÃES ${ }^{5}$
}

\begin{abstract}
RESUMO - A produção de café orgânico vem se constituindo uma tendência necessária e irreversível do agronegócio brasileiro. Essa atividade tem-se destacado como uma alternativa de renda para alguns cafeicultores, devido à crescente demanda mundial por alimentos mais saudáveis. Entretanto, grande parte das técnicas propostas pela agricultura orgânica está sendo aplicada empiricamente no cultivo de café, principalmente no Estado de Minas Gerais, maior região produtora de café do Brasil. Levando-se em consideração a baixa fertilidade natural dos solos dessa região cafeeira, bem como a elevada extração de nutrientes pelo cafeeiro, objetivou-se neste trabalho identificar possíveis fatores limitantes para a produção orgânica do cafeeiro, relacionados à fertilidade do solo e ao estado nutricional das plantas. Foram realizadas avaliações da fertilidade do
\end{abstract}

solo e análise das folhas em vinte e uma lavouras orgânicas representativas do Estado de Minas Gerais. As amostras de solo foram analisadas para determinação do $\mathrm{pH}$, acidez potencial e dos teores de $\mathrm{P}, \mathrm{K}, \mathrm{Ca}, \mathrm{Mg}, \mathrm{S}$, $\mathrm{Al}$ e matéria orgânica. As amostras foliares foram analisadas para determinação dos teores de N, P, K, Ca, $\mathrm{Mg}, \mathrm{S}, \mathrm{B}, \mathrm{Cu}, \mathrm{Fe}, \mathrm{Mn}$ e Zn. Com base nos padrões de interpretação para cafeeiros convencionais propostos pela literatura, estabeleceram-se as freqüências com que os caracteres analisados foram inferiores aos critérios de interpretação da fertilidade do solo e estado nutricional das plantas. A análise dos dados foi realizada por estatística descritiva. Novos trabalhos nessa nova área são necessários, visando a uma melhor interpretação da análise foliar e da fertilidade do solo, quando se trabalha com café orgânico.

TERMOS PARA INDEXAÇÃO: Café orgânico, análise de solo, análise foliar, Coffea arabica, diagnose nutricional.

\section{NUTRITIONAL DIAGNOSIS OF ORGANIC COFFEE AGROECOSYSTEMS IN THE MINAS GERAIS STATE}

\begin{abstract}
The production of organic coffee have been shown as a necessary and irreversible tendency of brazilian agrobusiness. This activity has an important role as an income alternative for some coffee producers, due to the increasing global demand for safety food. However the majority of techniques proposed in the organic agriculture have beeing use empiricaly to the coffee plantings, especialy in Minas Gerais state, the producer state coffee in Brazil. Considering the low natural soil fertility of this coffee region and the great nutrient exportation from the coffee crops, the objective of this research is to evaluate possible negative fators for the organic coffee production related with soil
\end{abstract}

fertility and the nutritional status of plants. Soil and leaf samples were collected in 21coffee plantings of Minas Gerais. The soil samples were analyzed for $\mathrm{pH}$, $\mathrm{P}, \mathrm{K}, \mathrm{P}, \mathrm{K}, \mathrm{Ca}, \mathrm{Mg}, \mathrm{S}, \mathrm{Al}$ and organic matter contents. Foliar samples were analyzed for $\mathrm{N}, \mathrm{P}, \mathrm{K}, \mathrm{Ca}, \mathrm{Mg}, \mathrm{S}$, $\mathrm{B}, \mathrm{Cu}, \mathrm{Fe}, \mathrm{Mn}$ and $\mathrm{Zn}$ contents. Considering the patterns established for conventional coffee plantings found in literature, frequencies were calculated when soil and leaf contents were low, high and adequate. The data were analyzed through descriptive statistics. More data is required on tissue analysis and soil fertility in order to effectively reveal nutritional disorders in organic coffee plantings.

1. Trabalho apresentado no XXVIII Congresso Brasileiro de Pesquisas Cafeeiras. Este trabalho contou com apoio financeiro da FAPEMIG.

2. Engenheiro Agrônomo, Doutoranda, UNIVERSIDADE FEDERAL DE LAVRAS/UFLA, Caixa Postal 37 - 37200-000 Lavras, MG. vantheodor@bol.com.br

3. Professora Titular do Departamento de Ciência do Solo da UFLA. janicegc@ufla.br

4. Engenheiro Agrônomo, MSc., Pesquisador do Departamento de Ciência do Solo da UFLA, jbcorrea@ufla.br

5. Professor Adjunto do Departamento de Agricultura da UFLA. rubensjg@ufla.br 


\section{INTRODUÇÃO}

Nas últimas três décadas, tem-se constatado que as commodities agrícolas tradicionais, como o café (Coffea arabica L.), requerem escalas de produção para compensar a queda estrutural de preços, bem como os custos crescentes de produção que resultam na redução das margens de lucro. Assim sendo, os sistemas de produção orgânica constituem-se em boa oportunidade, principalmente aos pequenos agricultores, pois embora utilizem mais mão-de-obra e apresentem uma menor produtividade que os sistemas convencionais, podem mostrar um desempenho econômico melhor, traduzido por menores custos efetivos, maiores relações benefíciocusto e maiores rendas efetivas (CARMO e MAGALHÃES, 1999).

Não existem dados consolidados a respeito da produção orgânica no Brasil. O BNDES realizou um estudo junto às principais certificadoras que atuam no País e a algumas empresas produtoras e/ou comercializadoras de produtos orgânicos, durante o ano de 2001, o que se caracterizou como a primeira aproximação sistematizada desses números. O levantamento indica a existência de 7.063 produtores certificados ou em processo de certificação no Brasil, em uma área de 269.718 ha, sendo $5,93 \%$ desses, produtores de café legitimamente orgânico (419 produtores), envolvendo uma área plantada de 13.005 ha $(4,82 \%$ do total $)$ (ORMOND et al., 2002). A Associação de Cafeicultura Orgânica do Brasil (ACOB/Machado/MG) estima que as exportações brasileiras em 2002 sejam de setenta mil sacas de sessenta quilos, o que representaria um salto de $191,0 \%$ sobre as exportações do ano anterior. Apesar do crescimento, os volumes exportados são pequenos, se comparados aos grandes negociadores internacionais, como o México, países da América Central e Peru, que concentram mais de $50 \%$ das vendas mundiais, avaliadas em um milhão de sacas por ano.

A viabilidade agronômica do sistema de produção de café orgânico em Minas Gerais foi comprovada por Theodoro (2001), estudando as alterações nas propriedades físicas, químicas e microbiológicas do solo em comparação ao solo original de um fragmento de mata nativa. Os resultados indicam uma maior fertilidade do solo para o café orgânico, seguido pelo café em conversão. Em relação à condição natural de ocorrência do solo estudado, os sistemas de produção do cafeeiro contribuem positivamente para a conservação dos atributos físicos após cinco anos de implantação da lavoura. Entre os parâmetros microbiológicos do solo avaliados, a colonização micorrízica não apresentou resulta- dos significativos e a biomassa carbono apresentou na época chuvosa maiores valores do que na época seca.

Embora o preço obtido na comercialização seja maior, geralmente os sistemas de produção orgânica do cafeeiro empregam maiores quantidades de mão-deobra e fertilizantes orgânicos, e sua produtividade pode ser menor que a dos sistemas convencionais. A diferença mais importante entre a cafeicultura orgânica e a convencional é que os produtores orgânicos restringem o uso de fertilizantes químicos e proíbem o uso de agrotóxicos, enquanto os produtores convencionais os utilizam intensivamente. Os produtores orgânicos usam maquinário moderno, adotam manejo integrado de pragas e manejo ecológico de doenças, variedades melhoradas, integração das adubações orgânica e verde, calagem, práticas recomendadas para a conservação do solo e da água e reciclagem de resíduos orgânicos de origem vegetal e animal (THEODORO et al., 2001).

A análise química do solo é o principal critério para avaliar sua fertilidade e, conseqüentemente, a necessidade de adubação para as culturas. A diagnose nutricional de plantas pode ser realizada pela avaliação dos resultados da análise química foliar, entre outros, constituindo-se numa ferramenta que permite planejar, avaliar e calibrar a recomendação de adubação utilizada nas lavouras. Dessa forma, a diagnose foliar consiste em um complemento da análise de solo, para a recomendação de fertilizantes, realizando de forma holística a avaliação dos fatores do solo e da planta, que poderiam estar limitando o crescimento, desenvolvimento e a produção do cafeeiro (CORRÊA et al., 2001).

Objetivou-se neste trabalho identificar os fatores relacionados ao estado nutricional das plantas e à fertilidade do solo, os quais são limitantes para a produção do cafeeiro orgânico no Estado de Minas Gerais.

\section{MATERIAL E MÉTODOS}

Foram selecionadas vinte e uma lavouras cafeeiras orgânicas representativas do Estado de Minas Gerais, nos municípios de Paraisópolis, Machado, Elói Mendes, Poço Fundo, Alfenas, Manhumirim, Jacuí e Santo Antônio do Amparo. Em cada lavoura foi demarcado um talhão de, no mínimo, um hectare, e foram selecionadas vinte e cinco plantas úteis. Em cada lavoura foi realizada amostragem de solo e de folhas.

\section{Avaliação da fertilidade do solo}

Em cada lavoura foi coletada uma amostra composta, formada por amostras de solo coletadas na proje- 
ção da copa das plantas úteis, na profundidade de $0-20 \mathrm{~cm}$. As amostras compostas foram analisadas quimicamente para determinação do $\mathrm{pH}$, acidez potencial e dos teores de fósforo, potássio, cálcio, magnésio, enxofre, alumínio e matéria orgânica, conforme metodologia descrita por Vettori (1969). Determinaram-se as freqüências com que as características analisadas foram inferiores aos critérios de interpretação da fertilidade do solo propostos pela CFSEMG (1999). As relações consideradas como adequadas foram $\mathrm{Ca} / \mathrm{Mg}(2,2)$; $\mathrm{Ca} / \mathrm{K}$ (6 a 8) e $\mathrm{Mg} / \mathrm{K}$ (2 a 3), conforme proposto por Malavolta et al. (1993). Foram adotadas também as relações $\mathrm{K} / \mathrm{CTC}_{\mathrm{pH}=7,0}$ de 3 a $4,5 \%$; $\mathrm{Ca} / \mathrm{CTC}_{\mathrm{pH}=7,0}$ de 45 a $55 \%$ e $\mathrm{Mg} / \mathrm{CTC}_{\mathrm{pH}=7,0}$ de 10 a $15 \%$.

\section{Diagnose nutricional}

Em cada lavoura foi coletada uma amostra foliar formada por quatro pares da terceira folha a partir da ponta/planta útil, coletadas nos quatro pontos cardeais, em ramos produtivos, na porção mediana do cafeeiro, quando os frutos entraram na fase de chumbinho, durante a primavera-verão. Após a coleta das folhas, essas foram analisadas quimicamente para determinação dos teores de N, P, K, Ca, Mg, S, B, Cu, Fe, Mn e Zn, conforme metodologia descrita por Sarruge e Haag (1974). Foram determinadas as freqüências com que os teores dos nutrientes analisados foram inferiores aos teores adequados para o cafeeiro propostos por Reuter e Robinson (1988), Jones Júnior et al. (1991), Bergmann (1992), Malavolta et al. (1993), Mills e Jones Júnior (1996), Malavolta et al. (1997) e CFSEMG (1999) (Tabelas 1 e 2). Foram considerados como os mais limitantes os dois nutrientes que apresentaram as maiores freqüências de lavouras com teores inferiores aos propostos como adequados pelos autores mencionados anteriormente.

Os dados foram analisados por meio de estatística descritiva.

TABELA 1 - Teores adequados de macronutrientes na folha de cafeeiro (C. arabica L.).

\begin{tabular}{lcccccc}
\hline & $\mathbf{N}$ & $\mathbf{P}$ & $\mathbf{K}$ & $\mathbf{C a}$ & $\mathbf{M g}$ & $\mathbf{S}$ \\
\hline & & & $\mathbf{g . k \mathbf { k g } ^ { - 1 }}$ \\
& $25-30$ & $1,5-2,0$ & $21-26$ & $7,5-15,0$ & $2,5-4,0$ & $0,2-1,0$ \\
Reuter \& Robinson (1988) & $23-30$ & $1,2-2,0$ & $20-25$ & $10-25$ & $2,5-4,0$ & $1,0-2,0$ \\
Jones Junior et al. (1991); Mills \& Jones & & & & & & \\
Junior (1996) & $27-30$ & $1,6-2,0$ & $21-23$ & $12-14$ & $3,0-4,0$ & $1,5-2,0$ \\
Bergmann (1992) & $27-32$ & $1,5-2,0$ & $19-24$ & $10-14$ & $3,1-3,6$ & $1,5-2,0$ \\
Malavolta et al. (1993) & $29-32$ & $1,6-1,9$ & $22-25$ & $13-15$ & $4,0-4,5$ & $1,5-2,0$ \\
Malavolta et al. (1997) & $29-32$ & $1,2-1,6$ & $18-22$ & $10-13$ & $3,1-4,5$ & $1,5-2,0$ \\
CFSEMG (1999) & & & & & & \\
\hline
\end{tabular}

TABELA 2 - Teores adequados de micronutrientes na folha de cafeeiro (C. arabica L.).

\begin{tabular}{lccccc}
\hline & B & Cu & Fe & Mn & Zn \\
\hline Reuter \& Robinson (1988) & \multicolumn{2}{c}{ mg.kg $^{-1}$} & & & \\
Jones Junior et al. (1991); Mills \& Jones Junior (1996) & $40-75$ & $10-25$ & $70-125$ & $50-200$ & $12-30$ \\
Bergmann (1992) & $50-100$ & $16-20$ & $70-200$ & $50-100$ & $15-30$ \\
Malavolta et al. (1993) & $59-60$ & $8-16$ & $90-180$ & $120-210$ & $8-16$ \\
Malavolta et al. (1997) & $50-60$ & $11-14$ & $100-130$ & $80-100$ & $15-20$ \\
CFSEMG (1999) & $40-80$ & $8-16$ & $70-180$ & $50-200$ & $10-20$ \\
\hline
\end{tabular}

Ciênc. agrotec., Lavras. V.27, n.6, p.1222-1230, nov./dez., 2003 


\section{RESULTADOS E DISCUSSÃO}

\section{Avaliação da fertilidade do solo}

De acordo com a CFSEMG (1999), na profundidade de $0-20 \mathrm{~cm}$, foram observados grandes freqüências de lavouras com acidez média $(66,7 \%)$ (Tabela 3) e teores médios de matéria orgânica (85,7\% das lavouras). Os valores foram classificados como bons em $61,9 \%$ das lavouras para a CTC efetiva, em $71,4 \%$ para a CTC a $\mathrm{pH} 7,0$ e em $52,4 \%$ para a soma de bases (Tabela 4).

Grande parte das lavouras cafeeiras analisadas apresentou teor muito baixo a nulo de $\mathrm{Al}$ no solo $(57,1 \%)$ (Tabela 3$)$, com consequiente predominância de valores muito baixos para a saturação desse elemento no solo $(76,2 \%)$ (Tabela 4). Os valores encontrados para o $\mathrm{P}$ remanescente registraram uma alta freqüência de teores muito bons $(57,1 \%)$ em relação aos teores baixos (9,5\%). O P Mehlich apresentou similaridade de resultados com o $\mathrm{P}$ remanescente em relação à freqüência de teores muito bons $(55,0 \%)$ e maior frequiência para teores baixos $(15,0 \%)$ (Tabela 3$)$.

Em relação às freqüências encontradas para teores médios de $\mathrm{P}$, foi detectada uma grande diferença entre o P Mehlich $(25,0 \%)$ e o P remanescente (4,9\%). A utilização da análise do $\mathrm{P}$ remanescente, juntamente com o P extraído pelo Mehlich, apresenta-se bastante interessante para agroecossistemas cafeeiros orgânicos, pois o $\mathrm{P}$ remanescente é uma análise complementar criada para auxiliar a interpretação da disponibilidade de P no solo, quando medida pelo extrator Mehlich. Solos que receberam fontes de $\mathrm{P}$ com solubilidade média (termofosfatos, arad, esterco de aves poedeiras), quando analisados pelo extrator Mehlich, podem apresentar resultados falsamente elevados (TOMÉ JÚNIOR, 1997).

Foram verificadas as frequiências de $47,6 \%$ para os teores médios e $23,8 \%$ para teores bons de potássio no solo. Os resultados para o magnésio registraram $33,3 \%$ de teores médios e $38,1 \%$ de teores altos, ao passo que o teor de cálcio no solo foi considerado alto em $52,4 \%$ das lavouras (Tabela 3 ). Os altos valores para as relações $\mathrm{Ca} / \mathrm{Mg}(63,6 \%)$ e $\mathrm{Ca} / \mathrm{K}(59,0 \%)$ (Tabela 5) apresentam correlação direta com a elevada frequiência de cafezais com alto teor de cálcio. A relação $\mathrm{Mg} / \mathrm{K}$ $(59,0 \%)$ (Tabela 5) também foi afetada diretamente pelos altos teores de magnésio. Como a freqüência de lavouras cafeeiras com alto teor de cálcio foi superior à de lavouras com alto teor de magnésio no solo, verificamse $63,6 \%$ de cafezais com altos valores da relação $\mathrm{Ca} / \mathrm{Mg}$ no solo (Tabela 5).

A maioria das lavouras apresentou baixos valores para as relações $\mathrm{Ca} / \mathrm{T}(81,8 \%), \mathrm{Mg} / \mathrm{T}(36,4 \%)$ e $\mathrm{K} / \mathrm{T}(50,0 \%)$ (Tabela 5). Os baixos valores das relações acima são atribuídos à grande frequiência de lavouras com teor médio de $\mathrm{H}+\mathrm{Al}(57,1 \%)$, visto que a acidez potencial faz parte do somatório que origina $\mathrm{T}$, aumentando o divisor ao se calcularem os valores das relações citadas.

As relações consideradas como adequadas foram $\mathrm{Ca} / \mathrm{Mg}(2,2)$; $\mathrm{Ca} / \mathrm{K}$ (6 a 8) e $\mathrm{Mg} / \mathrm{K}$ (2 a 3) e também foram adotadas as relações $\mathrm{K} / \mathrm{T}$ de 3 a $4,5 \%$; $\mathrm{Ca} / \mathrm{T}$ de 45 a $55 \%$ e $\mathrm{Mg} / \mathrm{T}$ de 10 a $15 \%$, conforme proposto por Malavolta et al. (1993).

TABELA 3 - Frequiência de valores de pH, teores de P, K, Ca, Mg e Al no solo na profundidade de 0-20 cm, em lavouras cafeeiras orgânicas do Estado de Minas Gerais (CFSEMG, 1999).

\begin{tabular}{lccccccc}
\hline \multicolumn{1}{r}{ Freqüiência de amostras } & $\mathbf{p H}$ & $\mathbf{P}_{(\text {Mehlich) }}$ & $\mathbf{P}_{(\text {(REM) }}$ & $\mathbf{K}$ & $\mathbf{C a}$ & $\mathbf{M g}$ & $\mathbf{A l}$ \\
\hline Com teores muito baixos (\%) & - & 5,0 & 19,0 & - & - & - & 57,1 \\
Com teores baixos (\%) & 10,2 & 15,0 & 9,5 & 9,6 & 9,6 & 4,8 & 14,3 \\
Com teores médios (\%) & 66,7 & 25,0 & 4,9 & 47,6 & 19,0 & 33,3 & 23,8 \\
Com teores bons & - & - & 9,5 & 23,8 & - & - & - \\
Com teores muito bons (\%) & - & 55,0 & 57,1 & 19,0 & - & - & - \\
Com teores altos (\%) & 23,1 & - & - & - & 52,4 & 38,1 & 4,8 \\
Com teores muito altos (\%) & & & & & 19,0 & 23,8 & - \\
\hline
\end{tabular}


TABELA 4 - Freqüência de valores de $\mathrm{H}+\mathrm{Al}$, matéria orgânica (MO), soma de bases (SB), CTC efetiva (t), CTC $\mathrm{pH}=7$ (T) e saturações de alumínio (m) e de base (V) no solo, na profundidade de 0-20 cm, em lavouras cafeeiras orgânicas do Estado de Minas Gerais (CFSEMG, 1999).

\begin{tabular}{lccccccc}
\multicolumn{1}{c}{ Freqüência de amostras } & $\mathbf{H}+\mathbf{A l}$ & $\mathbf{S B}$ & $\mathbf{t}$ & $\mathbf{T}$ & $\mathbf{m}$ & $\mathbf{M O}$ & $\mathbf{V}$ \\
\hline Com teores muito baixos $(\%)$ & - & - & - & - & 76,2 & - & 4,8 \\
Com teores baixos $(\%)$ & 4,8 & 4,8 & 4,8 & - & 14,3 & 9,5 & 33,3 \\
Com teores médios $(\%)$ & 57,1 & 23,8 & 33,3 & 23,8 & 9,5 & 85,7 & 28,6 \\
Com teores bons & - & 52,4 & 61,9 & 71,4 & - & - & 33,3 \\
Com teores muito bons $(\%)$ & - & 19,0 & - & 4,8 & - & - & - \\
Com teores altos $(\%)$ & 28,6 & - & - & - & - & 4,8 & - \\
Com teores muito altos $(\%)$ & 9,5 & - & - & - & - & -
\end{tabular}

TABELA 5 - Freqüência de lavouras orgânicas com valores baixo, médio e alto das relações $\mathrm{Ca} / \mathrm{T}, \mathrm{Mg} / \mathrm{T}, \mathrm{K} / \mathrm{T}$, $\mathrm{Ca} / \mathrm{Mg}, \mathrm{Ca} / \mathrm{K}$ e $\mathrm{Mg} / \mathrm{K}$ no solo, na profundidade de 0-20 cm no Estado de Minas Gerais.

\begin{tabular}{lcccccc}
\hline \multirow{2}{*}{ Freqüência de amostras } & $\mathbf{C a} / \mathbf{T}$ & $\mathbf{M g} / \mathbf{T}$ & $\mathbf{K} / \mathbf{T}$ & $\mathbf{C a} / \mathbf{M g}$ & $\mathbf{C a} / \mathbf{K}$ & $\mathbf{M g} / \mathbf{K}$ \\
\hline Com baixos valores (\%) & 81,8 & 36,4 & 50,0 & 13,6 & 13,7 & 13,8 \\
Com médios valores (\%) & 18,2 & 27,2 & 27,2 & 22,8 & 27,3 & 27,2 \\
Com altos valores (\%) & -- & 36,4 & 22,8 & 63,6 & 59,0 & 59,0 \\
\hline
\end{tabular}

\section{Diagnose nutricional}

Foram registradas diferentes diagnoses nutricionais do cafeeiro orgânico, de acordo com os teores adequados propostos por Reuter e Robinson (1988), Jones Júnior et al. (1991), Bergmann (1992), Malavolta et al. (1993), Mills e Jones Júnior (1996), Malavolta et al. (1997) e CFSEMG (1999) (Tabela 6).

Os nutrientes mais limitantes ao utilizar os teores adequados propostos por Reuter e Robinson (1988) foram o potássio e o zinco, pois apresentaram as maiores freqüências de lavouras com baixo teor (76,2\% e 80,9\%, respectivamente). Quando foram utilizados os teores adequados propostos por Jones Júnior et al. (1991) e Mills e Jones Júnior (1996), potássio $(72,7 \%)$ e cálcio $(77,3 \%)$ foram os nutrientes indicados como os mais limitantes. Cálcio $(95,5 \%)$ e Zinco $(86,4 \%)$ foram os nutrientes indicados como os mais limitantes, segundo os teores propostos por Bergmann (1992) (Tabela 6). Corrêa et al. (2001), em uma avaliação da fertilidade do solo e do estado nutricional de cafeeiros convencionais do sul de Minas Gerais, encontraram resultados similares aos encontrados neste trabalho em relação aos nutrientes mais limitantes citados anteriormente. 
Ressalta-se que os mesmos nutrientes (potássio e cálcio) foram registrados como limitantes de acordo com os padrões indicados por Jones Júnior et al. (1991), Mills e Jones Junior (1996) ( $\mathrm{K}=72,7 \%$; $\mathrm{Ca}=77,3 \%$ ), Malavolta et al. (1993) (freqüência K $=63,7 \% ; \mathrm{Ca}=77,3 \%)$, Malavolta et al. (1997) $(\mathrm{K}=$ 86,4\%; $\mathrm{Ca}=95,5 \%)$ e CFSEMG (1999) $(\mathrm{K}=45,4 \%$, $\mathrm{Ca}=72,7 \%$ ) (Tabela 6). Nota-se que quando os diferentes padrões indicaram os mesmos nutrientes como limitantes, as frequiências de lavouras com baixos teores de cálcio apresentaram certa similaridade de resultados, ao passo que os resultados para o potássio foram diferentes entre as diagnoses realizadas. A análise dos teores de enxofre com a utilização dos critérios propostos pelos autores acima apresentou uma igualdade em todas as freqüências obtidas, ou seja, $100 \%$ de amostras com altos teores (Tabela 6)

Os resultados encontrados para os teores de nitrogênio e suas respectivas freqüências obtidas para teores adequados, de acordo com Reuter e Robinson (1988) ( $\mathrm{N}=70 \%)$, Jones Júnior et al. (1991), Mills e Jones Júnior (1996) ( $\mathrm{N}=81,0 \%)$, Bergmann (1992) $(\mathrm{N}=66,7 \%)$, Malavolta et al. (1993) $(\mathrm{N}=$ 76,2\%), Malavolta et al. (1997) $(\mathrm{N}=47,6 \%)$ e CFSEMG (1999) $(\mathrm{N}=63,6 \%)$ (Tabela 6), refletem a boa eficiência do sistema orgânico de produção do cafeeiro no fornecimento de $\mathrm{N}$ às plantas, com a utilização de compostos orgânicos, adubação verde, roçada de plantas espontâneas e cobertura vegetal permanente do solo.

Como são diferentes os padrões fornecidos segundo esses autores, nota-se que, para um mesmo nutriente, foram obtidos resultados discrepantes, como, por exemplo, as freqüências de teores adequados para o Boro, segundo Reuter e Robinson (1988), foi de 95,2\%; Jones Júnior et al. (1991), Mills e Jones Júnior (1996) encontraram B $=81,8 \%$ e CFSEMG (1999) B =90,9\% (Tabela 6). Outros autores indicam para o Boro freqüências de teores al- tos, como Bergmann (1992) ( $\mathrm{B}=50,0 \%)$, Malavolta et al. (1993) ( $\mathrm{B}=50,0 \%)$ e Malavolta et al. (1997) (B = 50,0\%) (Tabela 6). É importante lembrar que o limite entre carência e excesso de Boro é sutil, ou seja, pode-se passar rapidamente de uma situação de deficiência para a toxidez.

Os altos teores de cobre encontrados segundo os padrões de Reuter e Robinson (1988) $(\mathrm{Cu}=$ $57,1 \%)$, Bergmann (1992) $(\mathrm{Cu}=86,4 \%)$, Malavolta et al. (1993) $(\mathrm{Cu}=86,4 \%)$, Malavolta et al. (1997) $(\mathrm{Cu}=91,0 \%)$ e CFSEMG (1999) $(\mathrm{Cu}=86,4 \%)$ (Tabela 6) podem estar relacionados à utilização de produtos à base de cobre (óxido cuproso, sulfato tribásico de cobre e hidróxido de cobre) para controle de doenças. Esse resultado ressalta a importância do plantio de variedades resistentes à ferrugem em agroecossistemas cafeeiros orgânicos, pois a utilização de produtos à base de cobre deve ser consultada previamente à entidade certificadora, sendo considerado um procedimento restrito que poderá ser proibido pelas normas da agricultura orgânica na próxima década. Carvalho et al. (2002) citam que é permitido o uso de $8 \mathrm{~kg}$ de cobre por hectare/ano até $31 / 12 / 2005$ e, a partir de $1 \% 1 / 2006$, o limite máximo será de $6 \mathrm{~kg}$ de cobre por hectare/ano.

Outro nutriente que apresentou as maiores freqüências para altos teores foi o manganês, segundo os padrões de Reuter e Robinson (1988) $(\mathrm{Mn}=$ 95,2 \%), Jones Júnior et al. (1991), Mills e Jones Júnior (1996) $(\mathrm{Mn}=59,1 \%)$, Bergmann (1992) $(\mathrm{Mn}=90,9 \%)$, Malavolta et al. (1993) $(\mathrm{Mn}=59,1$ \%), Malavolta et al. (1997) $(\mathrm{Mn}=86,4 \%)$ e CFSEMG (1999) $(\mathrm{Mn}=59,1 \%)($ Tabela 6). Excessos de manganês podem estar associados à calagem deficiente.

Com este trabalho, evidencia-se a importância da adoção das análises de solo e foliares como ferramentas de monitoração e recomendação de adubação do cafeeiro orgânico, visando a atingir seu equilíbrio nutricional. 
TABELA 6 - Freqüência de lavouras com baixos, médios e altos teores foliares de N, P, K, Ca, Mg, S, B, Cu, Fe, Mn e Zn, segundo as diagnoses fornecidas pelos padrões de Reuter e Robinson (1988), Jones Júnior et al. (1991), Bergmann (1992), Malavolta et al. (1993), Mills e Jones Júnior (1996), Malavolta et al. (1997) e CSEMG (1999).

\begin{tabular}{|c|c|c|c|c|c|c|c|c|c|c|c|}
\hline Freqüência (\%) & $\mathbf{N}$ & $\mathbf{P}$ & $\mathbf{K}$ & $\mathbf{C a}$ & Mg & $\mathbf{S}$ & B & $\mathbf{C u}$ & $\mathbf{F e}$ & Mn & $\mathbf{Z n}$ \\
\hline $\begin{array}{l}\text { Amostras com baixos teores }(\%) \\
\text { Reuter e Robinson (1988) }\end{array}$ & 5,0 & - & 76,2 & 14,3 & 4,7 & - & - & 9,6 & - & 4,8 & 80,9 \\
\hline $\begin{array}{l}\text { Amostras com teores adequados } \\
(\%) \text { Reuter e Robinson (1988) }\end{array}$ & 70,0 & 33,3 & 19,0 & 85,7 & 52,4 & - & 95,2 & 33,3 & 95,2 & - & 14,3 \\
\hline $\begin{array}{l}\text { Amostras com altos teores }(\%) \\
\text { Reuter e Robinson (1988) }\end{array}$ & 25,0 & 66,7 & 4,8 & - & 42,9 & 100 & 4,8 & 57,1 & 4,8 & 95,2 & 4,8 \\
\hline $\begin{array}{l}\text { Amostras com baixos teores (\%) } \\
\text { Jones Júnior et al. (1991), Mills e } \\
\text { Jones Júnior (1996) }\end{array}$ & - & - & 72,7 & 77,3 & - & - & 4,6 & 4,6 & - & - & 45,4 \\
\hline $\begin{array}{l}\text { Amostras com teores adequados } \\
\text { (\%) Jones Júnior et al. (1991), } \\
\text { Mills e Jones Júnior (1996) }\end{array}$ & 81,0 & 27,3 & 22,8 & 22,7 & 63,6 & - & 81,8 & 50,0 & 9,1 & 40,9 & 50,0 \\
\hline $\begin{array}{l}\text { Amostras com altos teores (\%) Jo- } \\
\text { nes Júnior et al. (1991), Mills e } \\
\text { Jones Júnior (1996) }\end{array}$ & 19,0 & 72,7 & 4,5 & - & 36,4 & 100 & 13,6 & 45,4 & 90,9 & 59,1 & 4,6 \\
\hline $\begin{array}{l}\text { Amostras com baixos teores (\%) } \\
\text { Bergmann (1992) }\end{array}$ & 14,3 & - & 72,8 & 95,5 & 4,5 & - & 4,5 & - & - & - & 86,4 \\
\hline $\begin{array}{l}\text { Amostras com teores adequados } \\
(\%) \text { Bergmann (1992) }\end{array}$ & 66,7 & 45,5 & 22,7 & 4,5 & 81,8 & - & 45,5 & 13,6 & - & 9,1 & 13,6 \\
\hline $\begin{array}{l}\text { Amostras com altos teores (\%) } \\
\text { Bergmann (1992) }\end{array}$ & 19,0 & 54,5 & 4,5 & - & 13,7 & 100 & 50,0 & 86,4 & - & 90,9 & - \\
\hline $\begin{array}{l}\text { Amostras com baixos teores (\%) } \\
\text { Malavolta et al. (1993) }\end{array}$ & 19,0 & - & 63,7 & 77,3 & 18,2 & - & 31,8 & - & 31,9 & 22,7 & 27,3 \\
\hline $\begin{array}{l}\text { Amostras com teores adequados } \\
(\%) \text { Malavolta et al. (1993) }\end{array}$ & 76,2 & 45,5 & 31,8 & 22,7 & 27,3 & - & 18,2 & 13,6 & 54,5 & 18,2 & 50,0 \\
\hline $\begin{array}{l}\text { Amostras com altos teores (\%) } \\
\text { Malavolta et al. (1993) }\end{array}$ & 4,8 & 54,5 & 4,5 & - & 54,5 & 100 & 50,0 & 86,4 & 13,6 & 59,1 & 22,7 \\
\hline $\begin{array}{l}\text { Amostras com baixos teores (\%) } \\
\text { Malavolta et al. (1997) }\end{array}$ & 47,6 & - & 86,4 & 95,5 & 54,6 & - & 4,5 & 4,5 & 45,4 & 4,5 & 77,3 \\
\hline $\begin{array}{l}\text { Amostras com teores adequados } \\
(\%) \text { Malavolta et al. (1997) }\end{array}$ & 47,6 & 18,2 & 9,1 & 4,5 & 31,8 & - & 45,5 & 4,5 & 36,4 & 9,1 & 4,5 \\
\hline $\begin{array}{l}\text { Amostras com altos teores (\%) } \\
\text { Malavolta et al. (1997) }\end{array}$ & 4,8 & 81,8 & 4,5 & - & 13,6 & 100 & 50,0 & 91,0 & 18,2 & 86,4 & 18,2 \\
\hline $\begin{array}{l}\text { Amostras com baixos teores (\%) } \\
\text { CFSEMG (1999) }\end{array}$ & 31,8 & - & 45,4 & 72,7 & 13,6 & - & - & - & - & - & 31,8 \\
\hline $\begin{array}{l}\text { Amostras com teores adequados } \\
\text { CFSEMG (1999) }\end{array}$ & 63,6 & - & 45,4 & 27,3 & 77,3 & - & 90,9 & 13,6 & 90,9 & 40,9 & 50,0 \\
\hline $\begin{array}{l}\text { Amostras com altos teores (\%) } \\
\text { CFSEMG (1999) }\end{array}$ & 4,6 & 100 & 9,2 & - & 9,1 & 100 & 9,1 & 86,4 & 9,1 & 59,1 & 18,2 \\
\hline
\end{tabular}




\section{CONCLUSÕES}

Em agroecossistemas cafeeiros orgânicos que utilizam fontes de $\mathrm{P}$ com solubilidade média, recomenda-se a realização da análise do $P$ remanescente, juntamente com o $\mathrm{P}$ extraído pelo Mehlich.

A eficiência do sistema orgânico de produção do cafeeiro no fornecimento de $\mathrm{N}$ às plantas, via compostos orgânicos, adubação verde, roçada de plantas espontâneas e cobertura vegetal permanente do solo, foi comprovada em razão das altas frequiências registradas para teores adequados de nitrogênio foliar.

Os altos teores de cobre encontrados nos cafeeiros orgânicos podem estar relacionados à utilização de produtos à base de cobre (óxido cuproso, sulfato tribásico de cobre e hidróxido de cobre) para controle de doenças. Esse resultado ressalta a importância do plantio de variedades resistentes à ferrugem em agroecossistemas cafeeiros orgânicos.

Recomendam-se mais trabalhos nessa nova área visando a uma melhor interpretação da análise foliar e da fertilidade do solo, quando trabalha-se com café orgânico, pois o manejo da lavoura é diferenciado em função da realidade edafo-climática de cada região.

\section{AGRADECIMENTOS}

À Fundação de Amparo à Pesquisa do Estado de Minas Gerais (FAPEMIG), pelos recursos cedidos para condução do projeto de pesquisa. À Associação de Cafeicultura Orgânica do Brasil (ACOB/Machado/MG), à Associação de Pequenos Produtores de Poço Fundo/MG, à EMATER de Manhumirim e Jacuí e aos cafeicultores orgânicos do Estado de Minas Gerais, que gentilmente cederam suas lavouras para coleta de dados e nos apoiaram durante todo o processo de pesquisa.

\section{REFERÊNCIAS BIBLIOGRÁFICAS}

BERGMANN, W. Nutritional disorders of plants: development, visual and analytical diagnosis. New York: G. Fisher, 1992. 741 p.

CARMO, M. S.; MAGALHÃES, M. M. Agricultura sustentável: avaliação da eficiência técnica e econômica de atividades agropecuárias selecionadas no sistema não convencional de produção. Informações Econômicas, São Paulo, v. 29, n. 7, p. 131, 1999.
CARVALHO, V. L. de; CUNHA, R. L. da; CHALFOUN, S. M. Manejo ecológico das principais doenças do cafeeiro. Informe Agropecuário, Belo Horizonte, v. 23, n. 214/215, p. 101-114, jan./abr. 2002.

COMISSÃO DE FERTILIDADE DO SOLO DO ESTADO DE MINAS GERAIS. Recomendações para o uso de corretivos e fertilizantes em Minas Gerais. 5. ed. Lavras, 1999. 359 p.

CORRÊA, J. B.; REIS JÚNIOR, R. A.; CARVALHO, J. G. de; GUIMARÃES, P. T. G. Avaliação da fertilidade do solo e do estado nutricional de cafeeiros do sul de Minas Gerais. Ciência e Agrotecnologia, Lavras, v. 25, n. 6, p. 1279-1286, nov./dez. 2001.

JONES JÚNIOR, J. B.; WOLF, B.; MILLS, H. A. Plant analysis hankbook. Athens: Micro-Macro, 1991. $213 \mathrm{p}$.

MALAVOLTA, E.; FERNANDEZ, D. R.; ROMERO, J. P. Seja doutor do seu cafezal. Informações Agronômicas, Campinas, v. 64, p. 1-13, 1993.

MALAVOLTA, E.; VITTI, G. C.; OLIVEIRA, S. A. Avaliação do estado nutricional das plantas: princípios e aplicações. 2. ed. Piracicaba: POTAFOS, 1997. $319 \mathrm{p}$.

MILLS, H. A.; JONES JÚNIOR, J. B. Plant analysis handbook II. 2. ed. Athens: Micro-Macro, 1996. $422 \mathrm{p}$.

ORMOND, J. G. P.; PAULA, S. R. L. de; FAVERET FILHO, P.; ROCHA, L. T. M. da. Agricultura orgânica: quando o passado é futuro. Rio de Janeiro: BNDES, 2002. 34 p. (Setorial, 15).

REUTER, D. J.; ROBINSON, J. B. Plant analysis: an interpretation manual. 2. ed. Melbourne: Inkata, 1988. $218 \mathrm{p}$.

SARRUGE, J. R.; HAAG, H. P. Análise química de plantas. Piracicaba: ESALQ/USP, 1974. 56 p.

THEODORO, V. C. de A. Caracterização de sistemas de produção de café orgânico, em conversão e convencional. 2001. 214 p. Dissertação (Mestrado em Agronomia/Fitotecnia) - Universidade Federal de Lavras, Lavras, 2001. 
THEODORO, V. C. de. A.; CAIXETA, I. F.; GUIMARÃES, R. J. Bases para a produção de café orgânico. Lavras: UFLA/CBP\&D/Café, 2001. 101 p.

TOMÉ JÚNIOR, J. B. Manual para interpretação de análise de solos. Guaíba: Agropecuária, 1997. 247 p.

VETTORI, L. Métodos de análise de solos. Rio de Janeiro: Ministério da Agricultura, 1969. 24 p. (MA. Boletim técnico, 7). 